\title{
Quantitative Investigation into the Influence of Temperature on Carbide and Austenite Evolution During Partitioning of a Quenched and Partitioned Steel
}

\author{
D. T. Pierce ${ }^{\mathrm{a}^{*}}$, D. R. Coughlin ${ }^{\mathrm{b}}$, D. L. Williamson ${ }^{\mathrm{c}}$, J. Kähkönen $^{\mathrm{d}}$, A. J. Clarke ${ }^{\mathrm{b}}$, K. D. Clarke ${ }^{\mathrm{b}}$, J. G. Speer ${ }^{\mathrm{d}}$, \\ E. De Moor ${ }^{\mathrm{d}^{*}}$ \\ ${ }^{a}$ Materials Science and Technology Division, Oak Ridge National Laboratory, 1 Bethel Valley Rd, Oak Ridge, TN \\ 37831, USA \\ ${ }^{b}$ Los Alamos National Laboratory, Materials Science and Technology Division, P.O. Box 1663, Los Alamos, NM \\ 87545, USA \\ ${ }^{c}$ Department of Physics, Colorado School of Mines, 1500 Illinois St., Golden, CO 80401, USA \\ ${ }^{d}$ Advanced Steel Processing and Products Research Center, Colorado School of Mines, 1500 Illinois St., Golden, \\ CO 80401, USA
}

*Corresponding Authors: D. T. Pierce, Tel.: (865) 574-7797, email: piercedt@ornl.gov

E. De Moor, Tel.: (303) 273-3624, email: edemoor@mines.edu

Key Words

Quenching and partitioning, transition carbides, Mössbauer spectroscopy, retained austenite, cementite

\begin{abstract}
The influence of partitioning temperature on microstructural evolution during quenching and partitioning was investigated in a $0.38 \mathrm{C}-1.54 \mathrm{Mn}-1.48 \mathrm{Si}$ wt.\% steel using Mössbauer spectroscopy and transmission electron microscopy. $\eta$-carbide formation occurs in the martensite during the quenching, holding, and partitioning steps. More effective carbon partitioning from martensite to austenite was observed at 450 than $400{ }^{\circ} \mathrm{C}$, resulting in lower martensite carbon contents, less carbide formation, and greater retained austenite amounts for short partitioning times. Conversely, greater austenite decomposition occurs at $450{ }^{\circ} \mathrm{C}$ for longer partitioning times. Cementite forms during austenite decomposition and in the martensite for longer partitioning times at $450{ }^{\circ} \mathrm{C}$.
\end{abstract}

The quenching and partitioning (Q\&P) steel heat treatment [1-3] produces microstructures containing primarily martensite (M) and retained austenite (RA) [4,5]. Q\&P involves quenching to a quench temperature (QT) between the martensite start $\left(\mathrm{M}_{\mathrm{s}}\right)$ and finish temperatures, partitioning at a temperature (PT) the same or higher temperature than the QT, followed by a final quench (FQ) to room temperature (RT) $[2,6]$. The goal is to partition carbon $(\mathrm{C})$ from martensite to austenite, thereby reducing the $\mathrm{C}$ supersaturation of the martensite and stabilizing the 
austenite before the FQ [6,7]. Experimental austenite amounts measured after Q\&P $[1,3,8]$ are often lower than values calculated assuming immobile martensite-austenite interfaces and/or all $\mathrm{C}$ in the martensite partitions to the austenite [6,9]. The discrepancy may be in large part due to austenite decomposition (e.g., by martensite-austenite interface movement and/or bainite formation) during the partitioning step [6,10-15] and/or incomplete $\mathrm{C}$ partitioning. The latter may result from competing tempering mechanisms, such as $\mathrm{C}$ trapping at defects [16], $\mathrm{C}$ clustering [17] and transition carbide and/or cementite $(\theta)$ formation [18,19]. The present authors identified $\eta$-carbide by transmission electron microscopy (TEM) and Mössbauer effect spectroscopy (MES) in 0.38C-1.54Mn$1.48 \mathrm{Si}$ wt.\% steel after partitioning at $400{ }^{\circ} \mathrm{C}$ for 10 and $300 \mathrm{~s}$ and developed novel MES spectral analysis techniques to enable the measurement of $\eta$-carbide amounts near 1 at. \% [19]. $\eta$-carbide quantities of 1.4 and 2.4 at.\% were measured after partitioning at $400{ }^{\circ} \mathrm{C}$ for 10 and $300 \mathrm{~s}$, respectively, which consumed 24 to $41 \%$ of the total bulk C, respectively [19].

The significant $\mathrm{C}$ consumption by carbides after partitioning at $400{ }^{\circ} \mathrm{C}$ for 10 or $300 \mathrm{~s}$ indicates that carbide formation competes with $\mathrm{C}$ partitioning from martensite to austenite. However, additional data are required to further understand the evolution of carbides during Q\&P [19]. MES revealed the fractional resonance due to Fe in carbides of a $1.22 \mathrm{wt} . \% \mathrm{C}$ steel increased with increasing tempering temperature during tempering for times of $1 \mathrm{~h}$ at temperatures from 150 to $300{ }^{\circ} \mathrm{C}[20,21]$. In contrast, increasing the PT from 250 to $400{ }^{\circ} \mathrm{C}$ during Q\&P processing of $0.60 \mathrm{C}-0.95 \mathrm{Mn}-1.96 \mathrm{Si}$ wt. $\%$ steel results in an increase in RA attributed to an apparent decrease in carbide formation, according to qualitative TEM observations $[8,22]$. Similarly, a lower apparent density of $\varepsilon$-carbides was observed by TEM in a sample of $0.3 \mathrm{C}-3.5 \mathrm{Mn}-1.6 \mathrm{Si}$ wt.\% steel partitioned at $400{ }^{\circ} \mathrm{C}$ for $60 \mathrm{~s}$ than after partitioning for $5 \mathrm{~s}$ [15]. The authors suggested that $\varepsilon$-carbides precipitated during the initial quench (IQ) decompose during isothermal holding at $400{ }^{\circ} \mathrm{C}$, resulting in an enhancement of the extent of $\mathrm{C}$ partitioning to austenite. Quantitative studies are required to further clarify how Q\&P processing parameters (e.g., PT and partitioning time (Pt)) and alloying (which is beyond the scope of this study), influence the trade-off between carbide formation and $\mathrm{C}$ partitioning. In the present work, previously developed quantitative MES methodologies [19] are employed to investigate the influence of $\mathrm{Pt}$ and $\mathrm{PT}$ on carbide formation and $\mathrm{C}$ partitioning from martensite to austenite in $0.38 \mathrm{C}$ 1.54Mn-1.48Si wt.\% (1.71C-1.52Mn-2.86Si at.\%) steel.

Samples were austenitized for $120 \mathrm{~s}$ at $850^{\circ} \mathrm{C}$, followed by quenching to approximately $250{ }^{\circ} \mathrm{C}$ and holding for $10 \mathrm{~s}$, then partitioning at 400 or $450{ }^{\circ} \mathrm{C}$ for $10,30,60$ and $300 \mathrm{~s}$. Quenching to $250{ }^{\circ} \mathrm{C}$ results in a calculated RA amount of 32 vol.\% [23,24]. Samples are designated QPXXX-YYY, where XXX and YYY refer to PT $\left({ }^{\circ} \mathrm{C}\right)$ and $\mathrm{Pt}(\mathrm{s})$, respectively. A water quenched sample (WQ) and sample quenched to $250{ }^{\circ} \mathrm{C}$ and held for $10 \mathrm{~s}$, followed by water quenching to RT (QP250-10), were also analyzed. Sample preparation, TEM, and MES procedures employed in this study are similar to those used previously [18,19], except where noted.

All MES spectra exhibited resonance due to martensite, austenite, and $\eta$-carbide. $\theta$ was detected in relatively small amounts in QP450-60 and in larger amounts in QP450-300. MES spectra for QP450-300 are shown in Fig. 1a and on an expanded scale in Fig. 1b. In Fig. 1a, stick diagrams representing the $\mathrm{A}(0,0), \mathrm{A}(0, n)$ and $\mathrm{A}(\mathrm{C})$ resonances are shown that correspond to Fe sites in austenite with zero $\mathrm{C}$ nearest neighbors (nn) and next nearest neighbors (nnn), with zero $\mathrm{C} n$ but with $n(n=1,2,3$ or 4) $\mathrm{C} n n n[19,25,26]$, and Fe with one $\mathrm{C} n n$ or two $\mathrm{C} n$ at 
adjacent sites $90^{\circ}$ from one another [27]. Stick diagrams showing representative line positions for stoichiometric $\left(\eta_{\mathrm{s}}\right)$ and non-stoichiometric $\eta$-carbide $\left(\eta_{\mathrm{ns}}\right)$, as well as $\theta$, are also denoted in Fig. 1a. Resonances corresponding to $\eta_{\mathrm{s}}$, $(\mathrm{Fe}, \mathrm{Mn}, \mathrm{Si})_{2} \mathrm{C}$, and $\eta_{\mathrm{ns}},(\mathrm{Fe}, \mathrm{Mn}, \mathrm{Si})_{3} \mathrm{C}$, are attributed to $\mathrm{Fe}$ atoms in $\eta$-carbide with three and two $\mathrm{C}$ nn, respectively $[19,28]$. The $\theta$ in QP450-60 and QP450-300 is assumed to be stoichiometric (Fe,Mn, $\mathrm{Si})_{3} \mathrm{C}[17,29]$. Despite the same stoichiometry, $(\mathrm{Fe}, \mathrm{Si}, \mathrm{Mn})_{3} \mathrm{C}$, the MES parameters of $\theta$ and $\eta_{\mathrm{ns}}$ are significantly different due to different lattice parameters and atom locations within their respective orthorhombic unit cells [28]. The levels of Si and Mn in the present steel result in significant fractions of Fe sites in carbides with 1 and $2 \mathrm{nn} \mathrm{Mn}$ and or Si atoms [30]. The nn Si and or Mn atoms are known to significantly reduce the magnetic hyperfine field $\left(\mathrm{B}_{\mathrm{hf}}\right)$ of Fe in $\theta[30,31]$ and might also influence the $\mathrm{B}_{\mathrm{hf}}$ of $\mathrm{Fe}$ in $\eta_{\mathrm{s}}$. In the present work, single sextets with broadened lines are employed to account for the total resonance, due to multiple different $F e$ sites in each of the $\eta_{\mathrm{s}}, \eta_{\mathrm{ns}}$, and $\theta$ resonances.

The $B_{h f}$ determined by MES for the $\eta_{\mathrm{s}}$ resonance of samples ranged from 16.9 to $17.4 \mathrm{~T}$, consistent with that of $17.4 \pm 0.5 \mathrm{~T}$ reported previously for this same alloy [19], and within the range of 16.2 [32] to $17.9 \mathrm{~T}$ [20] reported for $\eta_{\mathrm{s}}$. In [32] a distinction between $\varepsilon$ or $\eta$ was not made, but previous research suggests the resonance was due to $\eta_{\mathrm{s}}[19]$. The small fractions of the $\eta_{\mathrm{s}}$ resonance necessitated the isomer shift (IS) and quadrupole splitting (QS) be fixed at 0.16 and $-0.09 \mathrm{~mm} \mathrm{~s}^{-1}$, respectively [19]. The $\mathrm{B}_{\mathrm{hf}}$ of the $\eta_{\mathrm{ns}}$ resonance ranged from 25.1 to $25.6 \mathrm{~T}$, falling within the range of 23.7 to $25.7 \mathrm{~T}$ and reported previously [19,28,32]. Similarly, the small $\eta_{\mathrm{ns}}$ resonance necessitated that the IS and QS be fixed at 0.13 and $-0.36 \mathrm{~mm} \mathrm{~s}^{-1}$ [19], respectively. In samples QP450-60 and to a greater extent, QP450-300, carbide resonance distinct from $\eta_{\mathrm{s}}$ and $\eta_{\mathrm{ns}}$ is detected with a $\mathrm{B}_{\mathrm{hf}}$ that is $\sim 1-2 \mathrm{~T}$ higher than that measured for $\eta_{\mathrm{s}}$. This additional resonance, attributed to $\theta$, could not be detected by MES in other samples and $\theta$ was not observed by TEM in samples of this alloy partitioned at $400{ }^{\circ} \mathrm{C}$ in previous work [19]. Since additions of $\mathrm{Mn}$ and Si do not significantly influence the IS and QS of $\theta[30,33]$, these values are fixed at those for pure $\mathrm{Fe}_{3} \mathrm{C} \theta$, 0.18 and $0.02 \mathrm{~mm} \mathrm{~s}^{-1}$ [33], respectively. Conversely, $\mathrm{Mn}$ and $\mathrm{Si}$ additions significantly reduce the $\mathrm{B}_{\mathrm{hf}}$ of $\mathrm{Fe}$ in $\theta$ $[30,31]$ below the value for that of pure $\mathrm{Fe}_{3} \mathrm{C} \theta\left(20.7 \mathrm{~T}\right.$, [33]). As such, the $\theta$ and $\eta_{\mathrm{s}}$ resonances overlap significantly, making a precise quantification of the relative amounts complex. Consequently, a series of fits were conducted with possible ranges of $B_{h f}$, from $18.5 \mathrm{~T}$ to $19.6 \mathrm{~T}$ for $\theta$ and 16.9 to $17.4 \mathrm{~T}$ for $\eta_{\mathrm{s}}$, in order to estimate the average amounts and probable ranges of the fractions of each component. The fit that produced values of the relative amounts of $\theta$ and $\eta_{\mathrm{s}}$ resonance nearest to the average values was selected for the quantitative analysis and standard deviations in the relative amounts were assessed from all fits for QP450-60 and QP450-300, respectively. The overlap of the $\eta_{\mathrm{s}}$ and $\theta$ resonances is illustrated in Fig. 1b, which shows the area of the MES spectrum where the 2 and 5 lines of each carbide resonance are predominantly resolved. The recoilless fraction of 0.86 for $\theta$ used in the quantitative analysis was calculated using previous methodologies [19] and a Debye temperature of 538 K [34]. Recoilless fractions for martensite, austenite and $\eta$-carbide are $0.82,0.81$, and 0.89 , respectively [19].

TEM confirmed the presence of both $\eta$ and $\theta$ in QP450-300, along with highly dislocated ferrite, which likely corresponds to martensite, although the presence of some bainitic ferrite may also be possible. $\chi$-carbide was not observed. The $\eta$-carbides were predominantly present as plate-like precipitates in the martensite [19]. The bright-field (BF) image in Fig. 2a, recorded a few degrees from the [-13-1 $]_{\alpha}$ zone axis (ZA), shows two different 
"tempered" martensite laths with a small degree of misorientation. Plate-like $\eta$-carbides are present in both laths with their habit-plane-normals approximately parallel to $(-3-10)_{\alpha}$, consistent with a $(00-2)_{\alpha}$ habit plane for $\eta$-carbide as reported elsewhere [19,35]. Separating the two martensite laths is a region of predominately $\theta$ and ferrite. The dark-field (DF) image in Fig. 2b, generated using the (2-1-1) $)_{\theta},(2-2-1)_{\theta}$, and (2-3-1) $)_{\theta}$ reflections at the same foil orientation as Fig. 2a, shows a series of irregular, discrete, nano-scale cementite precipitates formed along the interlath region. The morphology of this inter-lath region suggests that an austenite film, separating the two martensite laths, may have been present upon the IQ but decomposed to $\theta$ and ferrite during the partitioning step, as no remaining austenite was observed in this area. In addition, discrete precipitates near or bordering the plate-like $\eta$ precipitates are visible in the DF image, suggesting the beginning of intra-lath $\theta$ precipitation that grew from $\eta$, consistent with similar observations in a Q\&T 1.5 wt.\% C alloy [36]. The presence of $\theta$ was also observed by TEM after tempering at $450{ }^{\circ} \mathrm{C}$ for $300 \mathrm{~s}$ in a $0.6 \mathrm{C}-2 \mathrm{Si}$ wt.\% steel [37]. The selected area diffraction pattern (SADP) in Fig. 2c corresponds to the $[-13-1]_{\alpha} \mathrm{ZA}$; the $(2-1-1)_{\theta},(2-2-1)_{\theta}$, and (2-3-1) $)_{\theta}$ reflections, along with faint $(-32-1)_{\eta}$ and $(-30-1)_{\eta}$ reflections, are indicated. The $[-11-1]_{\alpha}$ SADP in Fig. 2 d shows the $(30-1)_{\theta}$ reflection. The Bagaryatsky orientation relationship $\left([001]_{\theta}\left\|[0 \overline{1} 1]_{\alpha}:(010)_{\theta}\right\|(211)_{\alpha}\right)[38]$ and $\theta$ lattice parameters a=5.090, b=6.748 and $\mathrm{c}=4.524 \mathrm{~nm}$ were used for indexing.

Fig. 3a-f shows the amount of carbide and RA (reported as a percentage of the bulk Fe content, \% Fe, rather than at.\% as in [19]), austenite C content, and fraction of the total bulk C (FTC) in carbide, austenite and martensite+ferrite as a function of hold time at the QT (10 s) plus Pt for all samples after the FQ, as determined by MES. The amount of $\eta$-carbide and the FTC contained in $\eta$-carbide is calculated assuming that the two resonances associated with $\eta$-carbide correspond to Fe atoms with three (stoichiometric) and two (non-stoichiometric) $\mathrm{C}$ nn $[19,28]$. The RA C content, $\mathrm{x}_{\mathrm{c}}($ at.\%), is related to the ratio of Fe sites in austenite with zero C first nn to all Fe sites in the austenite, $\mathrm{r}(0)$, by $r(0)=\left(1-\frac{x_{c}}{1-x_{c}}\right)^{6}$. This equation assumes a random $\mathrm{C}$ distribution [20,39] and $\mathrm{C}$ contents determined via this method agree well with those obtained by XRD [19]. The FTC in martensite+ferrite, including C in both tempered and "fresh" martensite (FM) formed during the FQ, as well as $\mathrm{C}$ in any additional ferritic component, is determined by subtracting the fractions of $\mathrm{C}$ in the austenite and carbide from unity. The precision errors in the carbide and austenite amounts are equal to or smaller than the data symbols, except as noted with error calculated from statistical and repeatability analysis. The absolute uncertainty will be larger due to possible systematic errors in the thickness correction [19], recoilless fractions, and sample thickness non-uniformity.

The amounts of $\eta$-carbide for WQ and QP250-10 (Fig. 3a) are 0.8 and $1.0 \%$ Fe, respectively, indicating that the combined amount of $\eta$-carbide precipitation occurring by auto-tempering during the IQ and in FM during the FQ of QP250-10 is significant, while formation by tempering during the hold at the QT is less important. The amount of $\eta$-carbide ranges from 0.8 to $1.0 \%$ Fe for samples QP400-10, QP400-30 and QP400-60 and increases to $1.3 \% \mathrm{Fe}$ in QP400-300. The amount of RA reaches a maximum at $\sim 14 \% \mathrm{Fe}$ in QP400-60 and then decreases to 11 $\% \mathrm{Fe}$ in QP400-300, as shown in Fig. 3b, while the RA C content exhibits a monotonic increase from approximately 4.3 at.\% in QP400-10 to 6.1 at.\% in QP400-300. MES spectra from a 5.0C at.\% steel quenched and aged at $80^{\circ} \mathrm{C}$ [32] exhibited no detectable carbide resonance, suggesting the increase in $\eta$-carbide amount from QP400-30 to 
QP400-300 is due primarily to formation in the initial martensite during partitioning, rather than from FM.

In Fig 3d, the total amount of eta carbide in both QP450-10 and QP450-30 is $0.6 \% \mathrm{Fe}$, and is significantly lower than the amounts measured in QP400-10, QP400-30 and also QP250-10. While this behavior might initially be interpreted as confirmation of eta carbide dissolution during partitioning [15], the situation is more complicated. Clearly the PT of $450^{\circ} \mathrm{C}$ is associated with greater solubility of eta carbide [8], promoting greater partitioning of carbon from martensite to austenite relative to $400{ }^{\circ} \mathrm{C}$, which reduces the amount of $\mathrm{C}$ in the initial martensite (Fig. $3 \mathrm{c}$ and $\mathrm{f}$ ), and further reduces the driving force for $\eta$-carbide precipitation and or/growth. Finally, since more $\mathrm{C}$ is partitioned into the austenite at a $\mathrm{PT}$ of $450^{\circ} \mathrm{C}$, the average $\mathrm{M}_{\mathrm{s}}$ of the austenite at the beginning of the $\mathrm{FQ}$ in samples QP450-10 and QP450-30 is lower than in samples QP400-10, QP400-30, and is much lower than QP250-10. The lower $\mathrm{M}_{\mathrm{s}}[24]$ will cause $\mathrm{FM}$ to form later during the $\mathrm{FQ}$, resulting in less time for $\eta$-carbide precipitation in the FM [32], which may also contribute to the reduced $\eta$-carbide amounts in QP450-10 and QP450-30. Similar to a PT of $400{ }^{\circ} \mathrm{C}$, the amount of $\eta$-carbide also increases during partitioning at $450{ }^{\circ} \mathrm{C}$ from Pts of 30 to $300 \mathrm{~s}$, suggesting that any dissolution of $\eta$-carbide during the partitioning step was minimal, consistent with the presence of $\eta$-carbides in the "tempered" martensite of QP450-300. Nonetheless, dissolution of some $\eta$-carbide during the partitioning step cannot be completely discounted. HajyAkbary et al. [15] observed a qualitatively lower density of $\varepsilon$-carbides by TEM after partitioning at $400{ }^{\circ} \mathrm{C}$ for a Pt of $60 \mathrm{~s}$ compared to a Pt of $5 \mathrm{~s}$, albeit in a steel of different composition (0.3C-1.6Si-3.5Mn wt.\%), and suggested that transition carbides dissolved during the partitioning step. In the present work, the most likely explanation for this increase in $\eta$-carbide amount from Pts of 30 to $300 \mathrm{~s}$ is a change in dynamics between $\mathrm{C}$ partitioning from martensite to austenite and $\eta$-carbide precipitation with increasing Pt. Toji et al. [29] examined 1.07C-2.2Si-2.9Mn and 0.59C-2.0Si-2.9Mn steels after Q\&T and reported that the average austenite $\mathrm{C}$ content was $\sim 1.2 \mathrm{wt}$.\% after tempering, regardless of bulk alloy $\mathrm{C}$ content or austenite volume fraction at the start of tempering, and that initial austenite volume is inversely related to carbide precipitation. These findings suggest carbide formation could become more favorable relative to $\mathrm{C}$ partitioning from martensite to austenite in the present alloy with increasing $\mathrm{Pt}$ as the amount of austenite decreases during partitioning (due to decomposition) and the austenite becomes more $\mathrm{C}$ enriched.

The amount of $\theta$ increases from $0.3 \% \mathrm{Fe}$ in QP450-60 to $2.0 \% \mathrm{Fe}$ in QP450-300. The peak amount of RA at the $450{ }^{\circ} \mathrm{C}$ PT is $17 \% \mathrm{Fe}$ in QP450-10 and QP450-30 (Fig. 3e), which is significantly larger and occurs at shorter Pts compared to a PT of $400{ }^{\circ} \mathrm{C}$, attributed to greater amounts of $\mathrm{C}$ partitioned into the austenite (Fig. 3) at $450{ }^{\circ} \mathrm{C}$. The RA amounts decrease to 14 and $5 \% \mathrm{Fe}$ in QP450-60 and QP450-300, respectively, indicating significantly greater rates of austenite decomposition at $450{ }^{\circ} \mathrm{C}$ compared to $400{ }^{\circ} \mathrm{C}$ from Pts between 30 and $300 \mathrm{~s}$. The decrease in austenite amounts for Pts greater than $30 \mathrm{~s}$ is accompanied by a significant decrease in austenite $\mathrm{C}$ content and increases in the amount of $\theta$. Generally, austenite decomposes to ferrite and/or $\theta$ [20] (or $\chi$-carbide [21]) during the second stage of tempering [40]. The FTC in (martensite + ferrite $+\eta$-carbide), austenite, and $\theta$ in QP450-30 is 0.43 , 0.57 , and 0 , respectively, and is assumed to be $<0.43,>0.57$ and 0 in this sample at the start of the FQ. In comparison, the FTC in (martensite + ferrite $+\eta$-carbide), austenite, and $\theta$ in QP450-300 is $0.52,0.10$, and 0.38, respectively. These findings indicate the majority of $\theta$ formation results from austenite decomposition, consistent 
with the interpretation of Fig. 2. The formation of $\theta$ during austenite decomposition decreases the average $\mathrm{C}$ content of the remaining austenite significantly below 5.0 at.\% [32] with increasing Pt from 30 to $300 \mathrm{~s}$, resulting in an increase in the $\mathrm{M}_{\mathrm{s}}$ [24]. This may cause a greater relative fraction of austenite to transform to FM earlier during the FQ and result in increased time for $\eta$-carbide precipitation in the FM, potentially contributing to the increase in $\eta$ carbide amounts by auto-tempering in QP450-300.

In summary, MES and TEM were performed to characterize the evolution of carbide and austenite in a 0.38C-1.54Mn-1.48Si wt.\% steel during Q\&P at PTs of 400 and $450{ }^{\circ} \mathrm{C}$. $\eta$-transition carbide formation occurs during the quenching, holding, and partitioning steps. $\eta$-carbide formation was reduced at shorter Pts at $450{ }^{\circ} \mathrm{C}$, compared to $400{ }^{\circ} \mathrm{C}$, owing in part to greater partitioning of $\mathrm{C}$ from martensite to austenite. Austenite decomposition to ferrite and cementite occurs during the partitioning step and is substantially greater at a PT of $450{ }^{\circ} \mathrm{C}$. Consequently, the largest amounts of austenite were retained after short Pts at $450{ }^{\circ} \mathrm{C}$.

\section{Acknowledgements}

This work was supported by the U.S. Department of Energy Advance Manufacturing Office under Award Number DE-EE0005765. DTP, JGS, and EDM gratefully acknowledge the support from the sponsors of the Advanced Steel Processing and Products Research Center (ASPPRC), an industry/university cooperative research center. DRC, KDC, and AJC gratefully acknowledge support from Los Alamos National Laboratory, operated by Los Alamos National Security, LLC under Contract No. DE-AC52-06NA25396 for the U.S. Department of Energy.

\section{Disclaimer}

This report was prepared as an account of work sponsored by an agency of the United States Government. Neither the United States Government nor any agency thereof, nor any of their employees, makes any warranty, express or implied, or assumes any legal liability or responsibility for the accuracy, completeness, or usefulness of any information, apparatus, product, or process disclosed, or represents that its use would not infringe privately owned rights. Reference herein to any specific commercial product, process, or service by trade name, trademark, manufacturer, or otherwise does not necessarily constitute or imply its endorsement, recommendation, or favoring by the United States Government or any agency thereof. The views and opinions of authors expressed herein do not necessarily state or reflect those of the United States Government or any agency thereof.

\section{References}

[1] J. G. Speer, A. M. Streicher, D. K. Matlock, F. Rizzo, G. Krauss, Quenching and Partitioning: A Fundamental New Process to Create High Strength Trip Sheet Microstructures, in: E. B. Damm and M. Merwin (Eds.), Austenite Formation and Decomposition, TMS/ISS, Warrendale, 2003, pp. 505-522.

[2] J. G. Speer, D. K. Matlock, B. De Cooman, J. G. Schroth, Acta Mat. 51 (2003) 2611-2622.

[3] J. G. Speer, D. V. Edmonds, F. C. Rizzo, D. K. Matlock, Curr. Opin. Solid St. M. 8 (2004) 219-237.

[4] D. K. Matlock, J. G. Speer, Design Considerations for the Next Generation of Advanced High Strength Steels, in: Proc. of The 3rd International Conference on Advanced Structural Steels, Korean Institute of Metals and Materials, Seoul, South Korea, 2006, pp. 774-781. 
[5] J. G. Speer, E. De Moor, K. O. Findley, D. K. Matlock, B. C. De Cooman, D. V. Edmonds, Metall. Mater. Trans. A. 42 (2011) 3591-3601.

[6] A. J. Clarke, J. G. Speer, M. K. Miller, R. E. Hackenberg, D. V. Edmonds, D. K. Matlock, F. C. Rizzo, K. D. Clarke, E. De Moor, Acta Mat. 56 (2008) 16-22.

[7] Y. Toji, H. Matsuda, M. Herbig, P.-P. Choi, D. Raabe, Acta Mat. 65 (2014) 215-228.

[8] D. V. Edmonds, K. He, F. C. Rizzo, B. C. De Cooman, D. K. Matlock, J. G. Speer, Mater. Sci. Eng A. 438440 (2006) 25-34.

[9] T. D. Bigg, D. K. Matlock, J. G. Speer, D. V. Edmonds, Sol. St. Phen. 172-174 (2011) 827-832.

[10] E. De Moor, C. Föjer, J. Penning, A. J. Clarke, J. G. Speer, Phys. Rev. B 82 (2010) 104210 1-5.

[11] E. De Moor, J. G. Speer, D. K. Matlock, C. Föjer, J. Penning, Effect of Si, Al and Mo Alloying on Tensile Properties Obtained by Quenching and Partitioning, in: Proc. Materials Science and Technology, Pittsburgh, 2009, pp. 1554-1563.

[12] E. De Moor, C. Föjer, A. J. Clarke, J. Penning, J. G. Speer, Quench \& partitioning response of a Mo-alloyed CMnSi steel, in: T. Perez (Ed.), Proc. New Developments on Metallurgy and Applications of High Strength Steels, Minerals, Metals and Materials Society, Buenos Aires, 2008, pp. 721-729.

[13] M. J. Santofimia, J. G. Speer, A. J. Clarke, L. Zhao, J. Sietsma, Acta Mat. 57 (2009) 4548-4557.

[14] D. De Knijf, M. J. Santofimia, H. Shi, V. Bliznuk, C. Föjer, R. Petrov, W. Xu, Acta Mat. 90 (2015) 161-168.

[15] F. HajyAkbary, J. Sietsma, G. Miyamoto, T. Furuhara, M. J. Santofimia, Acta Mat. 104 (2016) 72-83.

[16] G. R. Speich, "Tempering of Low-Carbon Martensite," in Trans. Metall. Soc. AIME, 1969.

[17] A. J. Clarke, M. K. Miller, R. D. Field, D. R. Coughlin, P. J. Gibbs, K. D. Clarke, D. J. Alexander, K. A. Powers, P. A. Papin, G. Krauss, Acta Mat. 77 (2014) 17-27.

[18] D. R. Coughlin, D. T. Pierce, J. G. Speer, A. J. Clarke, P. D. Jablonski, O. Dogan, V. K. Judge, E. De Moor, K. D. Clarke, Transition Carbide Formation in a 0.2C-1.54Mn-1.48Cr-1.30Si (wt. pct.) Quenched and Partitioned Steel, in: Matthias Militzer, Gianluigi Botton, Long-Qing Chen, James Howe, Chadwick Sinclair, and Hatem Zurob (Eds.), Proc. of the International Conference on Solid-Solid Phase Transformations in Inorganic Materials, Whistler, 2015, pp. 1051-1058.

[19] D. T. Pierce, D. R. Coughlin, D. L. Williamson, K. D. Clarke, A. J. Clarke, J. G. Speer, E. De Moor, Acta Mat. 90 (2015) 417-430.

[20] D. L. Williamson, K. Nakazawa, G. Krauss, Metall. Trans. A. 10 (1979) 1351-1363.

[21] C.-B. Ma, T. Ando, D. L. Williamson, G. Krauss, Metall. Trans. A. 14 (1983) 1033-1045.

[22] D. V. Edmonds, K. He, M. K. Miller, F. C. Rizzo, A. Clarke, D. K. Matlock, J. G. Speer, Mater. Sci. Forum. 
$539-543$ (2007) 4819-4825.

[23] D. P. Koistinen, R. E. Marburger, Acta Metall. 7 (1959) 59-60.

[24] S. M. C. van Bohemen, Mater Sci Tech Ser. 28(4) (2012) 487-495.

[25] P. Bauer, O. N. C. Uwakweh, J. M. R. Génin, Hyperfine Interact. 41 (1998) 555-558.

[26] O. N. C. Uwakweh, J. P. Bauer, J.-M. R. Génin, Metall Trans A. 21 (1990) 589-602.

[27] K. Oda, H. Fujimura, H. Ino, J. Phys-Condens. Mat. 6 (1994) 679-692.

[28] G. Le Caër, J. M. Dubois, M. Pijolat, V. Perrichon, P. Bussière, J. Phys. Chem. 86 (1982) 4799-4808.

[29] Y. Toji, G. Miyamoto, D. Raabe, Acta Mat. 86 (2015) 137-147.

[30] P. Schaaf, S. Wiesen, U. Gonser, Acta Metall. Mater. 40 (1992) 373-379.

[31] J. H. Jang, I. G. Kim, H. Bhadeshia, Comp. Mater. Sci. 44 (2009) 1319-1326.

[32] H. Ino, T. Ito, S. Nasu, U. Gonser, Acta Metall. 30 (1982) 9-20.

[33] G. Le Caër, J. M. Dubois, J. P. Senateur, J. Solid State Chem. 19 (1976) 19-28.

[34] C. K. Ande, First-Principles Calculations on the Stabilization of Iron Carbides $\left(\mathrm{Fe}_{3} \mathrm{C}, \mathrm{Fe}_{5} \mathrm{C}_{2}\right.$ and $\left.\eta-\mathrm{Fe}_{2} \mathrm{C}\right)$ in Steels, Technische Universiteit Delft, Delft, 2013.

[35] J. Imai, Trans. JIM. 16 (1975) 721-734.

[36] Y. Nakamura, S. Nagakura, T. Jpn. I. Met. 27 (1986) 842-848.

[37] G. Miyamoto, J. C. Oh, K. Hono, T. Furuhara, T. Maki, Acta Mat. 55 (2007) 5027-5038.

[38] H. Bhadeshia, Worked examples in the geometry of crystals, The Institute of Metals, London, 2001.

[39] D. T. Pierce, D. R. Coughlin, D. L. Williamson, K. D. Clarke, A. J. Clarke, J. G. Speer, D. K. Matlock, E. De Moor, Mössbauer spectroscopy investigation of transition carbides in quenched and partitioned steel, in: Matthias Militzer, Gianluigi Botton, Long-Qing Chen, James Howe, Chadwick Sinclair, and Hatem Zurob (Eds.), Proc. of the International Conference on Solid-Solid Phase Transformations in Inorganic Materials, Whistler, 2015, pp. 91-98.

[40] G. Krauss, STEELS: Processing, Structure, and Performance, ASM International, Materials Park, 2005. 

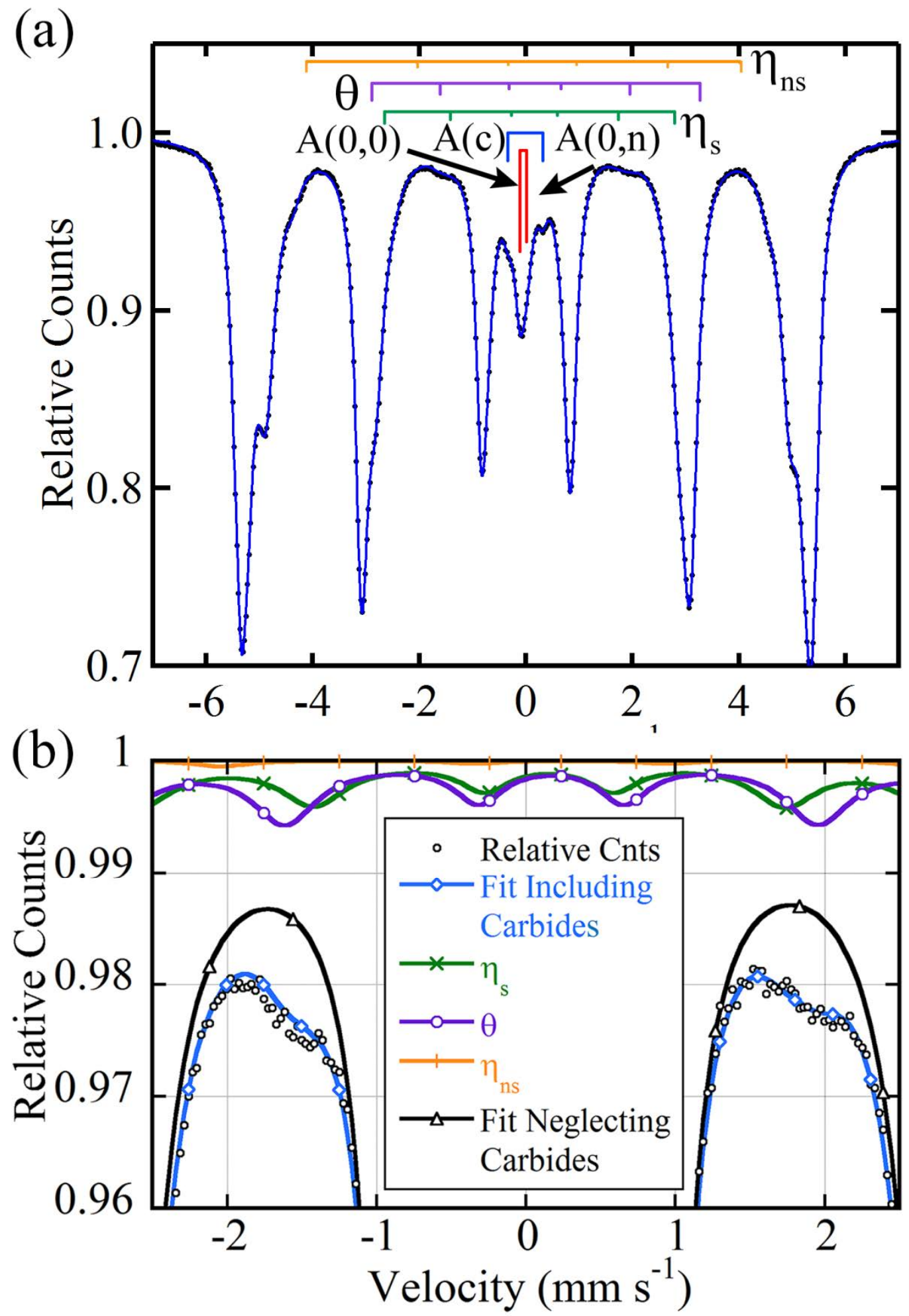

Fig. 1 MES spectra for QP450-300 shown on (a) full velocity range and (b) expanded scale. In (a), the stick diagrams representing the carbide and austenite resonances are not to scale. The solid line through the experimental data points is fitted by summation of all subspectra. In (b), the relative counts, carbide subspectra, and fit including and neglecting carbides are shown. Other subspectra removed for clarity. Zero velocity represents the center of the pure $\alpha$-iron calibration spectrum. 


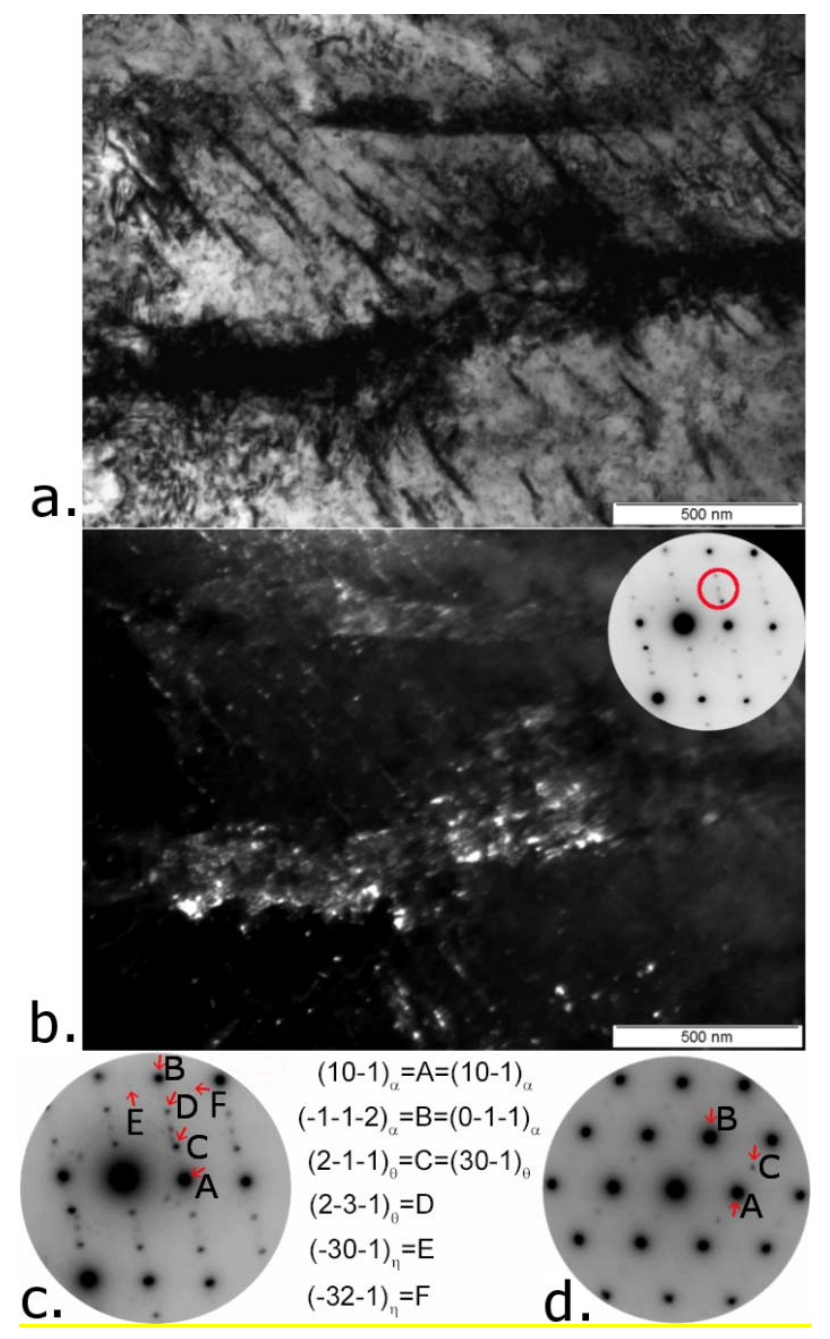

Fig. 2 (a) BF image recorded near the [-13-1 $]_{\alpha}$ ZA and (b) corresponding DF image created using the $(2-1-1)_{\theta},(2-2-1)_{\theta}$, and $(2-3-1)_{\theta}$ reflections from the [-13-1 $]_{\alpha}$ SADP. (c) $[-13-1]_{\alpha}$ and (d) $[-11-1]$ SADPs both recorded from the region within (a). 

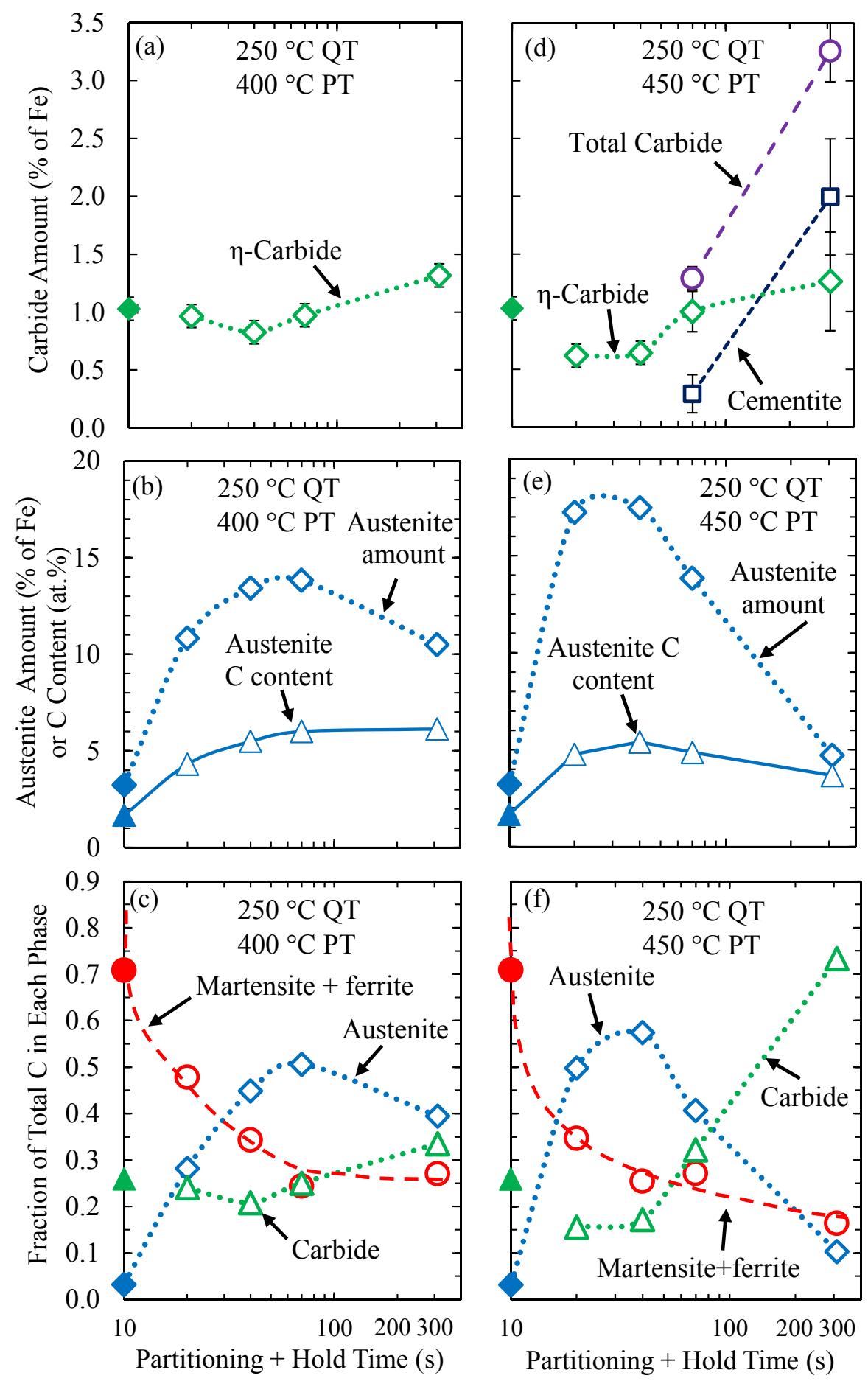

Fig. 3 MES quantitative results. (a,d) carbide amount, (b,e) austenite amount and $\mathrm{C}$ content, and (c,f) FTC in each phase vs. Pt + hold time at the QT for PTs of 400 (left) and $450{ }^{\circ} \mathrm{C}$ (right). QP250-10 indicated by filled symbols. 
Graphical Abstract
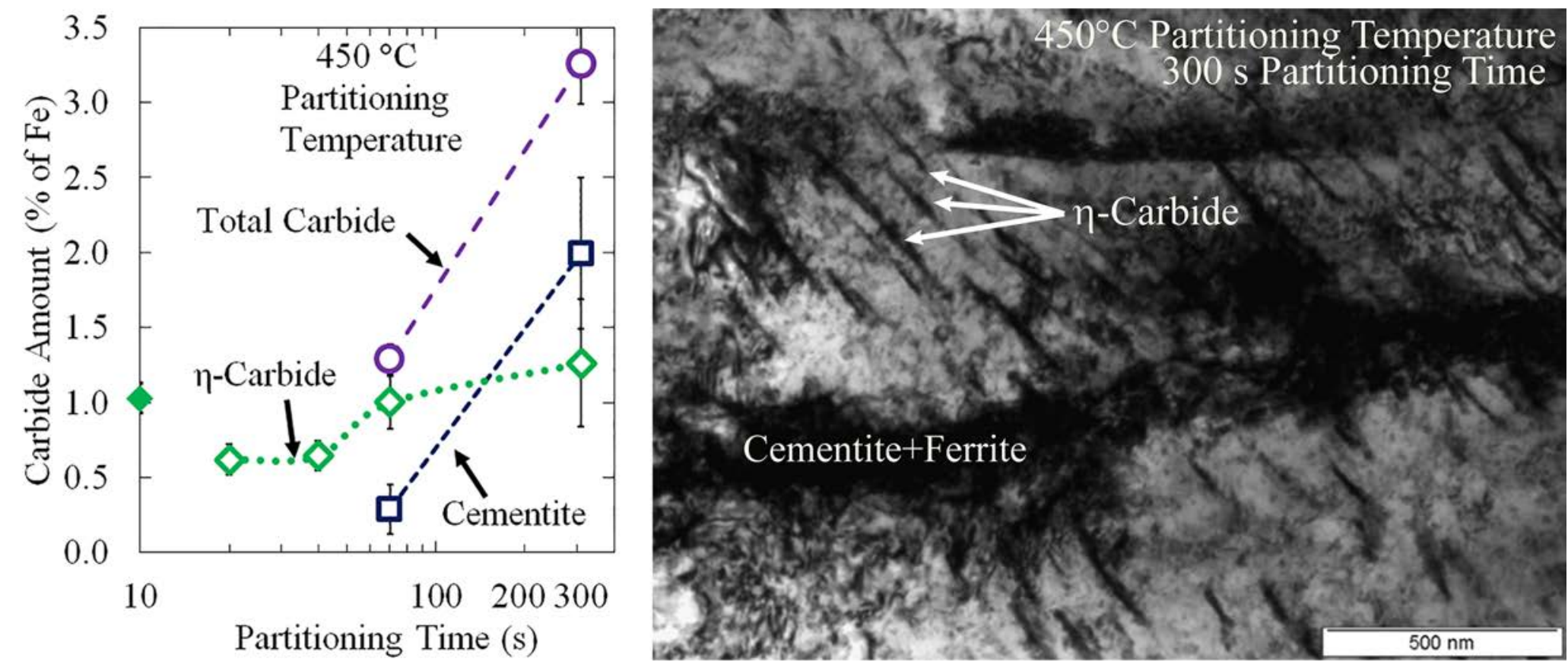